\title{
Recognition of Advanced Practice Pharmacists in Australia and Beyond: Considerations for Canadian Practitioners
}

\author{
Rochelle M Gellatly and Kirsten Galbraith
}

\section{INTRODUCTION}

$\mathrm{T}$ The concept of advanced pharmacy practice has been of national and international interest for many years as a means to address increases in patient complexity and changes in health care systems. Comorbidities are often considered as a factor in complexity, and the prevalence of Canadians and Australians living with 2 or more comorbidities is rising. ${ }^{1-3}$ More than twothirds $(65.7 \%)$ of Canadian seniors and more than one-third (36.1\%) of Australian seniors take at least 5 different prescription medications, further adding to their complexity. ${ }^{4,5}$

In 2019, it was predicted that Canada would spend approximately $\$ 264.4$ billion on health care ( $\$ 7068$ per resident), with the cost of medications making up the third-largest portion of this expenditure. ${ }^{6}$ Australia is also facing significant challenges in its health care system, with per capita health care expenditures similar to those in Canada. ${ }^{7}$ With these increasing costs and patient complexity, there is demand for pharmacists to develop a more advanced practice, one that extends beyond entry to the profession. ${ }^{8}$ This demand has been recognized by the Australian pharmacy profession and has led to the development and implementation of the Advanced Pharmacy Practice Framework (APPF). ${ }^{9}$

The Canadian Journal of Hospital Pharmacy's Advanced Pharmacist Practitioner Series, of which this article is a part, aims to engage readers with this topic as a means of inspiring action to optimize pharmacy practice, addressing both the gaps in the Canadian health care system and the needs of patients. Furthermore, a report from the Pharmacy Thought Leadership Summit, held in 2016, identified advanced practice as part of the solution to optimize pharmacy practice in Canada. ${ }^{10}$ This solution includes clearly defining advanced practice and specialization, as well as developing a national certification and formal recognition process for specialty and advanced practice. The aim of this article is to describe the Australian approach to recognizing advanced pharmacy practice, the global development of advanced practice, and considerations for the Canadian pharmacy profession in adopting a formal recognition process.

\section{BACKGROUND}

\section{Development of the APPF}

The first steps for the Australian pharmacy profession were to define advanced practice and develop a framework outlining such a practice. The APPF, released in 2012, described advanced practice as "practice that is so significantly different from that achieved at initial registration that it warrants recognition by professional peers and the public of the expertise of the practitioner and the education, training and experience from which that capability was derived." 9

All pharmacy bodies in Australia collaborated on the APPF, which describes 30 competencies across the 5 domains of professionalism and ethics, communication and collaboration, medicines management and patient care, leadership and management, and education and research. ${ }^{9}$ The competencies within the domains are mapped against 3 stages of performance (Table 1). ${ }^{11}$ The APPF drew from pre-existing frameworks in Australia with focused scopes of practice, as well as the domains in the UK Competency Development and Evaluation Group's Advanced and Consultant Level Competency Framework., ${ }^{9,12}$ Not only was 
Table 1. Advancing Practice Credentialing Stages ${ }^{11}$

\begin{tabular}{|c|c|c|}
\hline Stage & Definition & Credential \\
\hline $\begin{array}{l}\text { Stage I Advancing } \\
\text { Practice }\end{array}$ & $\begin{array}{l}\text { Performing at a stage of advancement } \\
\text { beyond early years of practice. }\end{array}$ & $\operatorname{AdvPP}(I)$ \\
\hline $\begin{array}{l}\text { Stage II Advancing } \\
\text { Practice }\end{array}$ & $\begin{array}{l}\text { An experienced and recognized local } \\
\text { leader with proven expertise in an area } \\
\text { of practice and capable of consistently } \\
\text { managing complex situations. }\end{array}$ & AdvPP(II) \\
\hline $\begin{array}{l}\text { Advanced Practice } \\
\text { Pharmacist }\end{array}$ & $\begin{array}{l}\text { A nationally and/or internationally } \\
\text { recognized leader with a breadth of } \\
\text { experience and expertise. }\end{array}$ & AdvPracPharm \\
\hline
\end{tabular}

the APPF developed to assist the profession in meeting the changing health care needs of Australians, it was also recognized as a tool for assuring the public of the competence and safety of advanced pharmacists. ${ }^{12}$

In 2015, a Credentialing of Advanced Practice Pharmacists pilot program was undertaken. ${ }^{13}$ Candidates submitted professional practice portfolios consisting of evidence of accomplishments with context and impact statements, mapped against the 3 stages of the 30 advanced practice competencies. ${ }^{9}$ During the pilot program, trained evaluators examined 43 portfolios with reference to the APPF competencies to establish practitioner performance. Twenty-eight pharmacists were recognized as "Advanced Practice Pharmacists" and agreed to have their names listed on a public website. ${ }^{14}$ The pilot program demonstrated that the framework was adaptable and relevant to evaluate performance in all areas of pharmacy practice. ${ }^{15}$ The APPF has since been integrated into Australia's National Competency Standards Framework for Pharmacists (NCSFP). ${ }^{16}$ This document now serves as the framework to describe a pharmacist's performance and development goals at any stage of their career.

\section{Canadian and Australian Health Care and Pharmacy Practice}

To further contextualize the discussion of advancing practice, it is important to understand the Australian health care system and pharmacy practice. Moles and Stehlik ${ }^{17}$ have previously completed a comprehensive review. The Australian health care system is funded both publicly and privately. Australia's Medicare program provides nationally subsidized primary care and publicly funded treatment in public hospitals. ${ }^{17}$ Private health insurance covers private hospitalizations and other health care-related services and items. In Canada, the medicare system is publicly funded. ${ }^{18}$ Both Australia and Canada have subsidized medicines programs; Canada's is delivered at the provincial or territorial level, whereas Australia's is delivered nationally. ${ }^{17,18}$

The pharmacist density in Australia and Canada is similar (Australia with 12.59 and Canada with 11.74 pharmacists per 10000 population). ${ }^{19}$ Most pharmacists work in community practice (63\% in Australia versus $70 \%$ in Canada), with a smaller proportion practising in hospitals (18\% in Australia versus 15\% in Canada), followed by other sectors including education, industry, and government. ${ }^{20,21}$ Aligned with Canadian practice, Australian pharmacists within hospital and community settings deliver dispensing and patient-centred clinical pharmacy services. Recently, the Society of Hospital Pharmacists of Australia established a national Foundation Residency Program, and it is developing Advanced Training Residencies. ${ }^{22}$ These experiential programs are aligned with the NCSFP and are similar in scope to the Canadian postgraduate year 1 and year 2 residency programs, respectively. ${ }^{16}$ Programs in both countries provide a professional linkage that engages the future workforce in recognition of their professional capabilities; the Australian programs are more overtly linked to recognition of advancing practice.

\section{CURRENT STATE}

\section{Advanced Practice Recognition in Australia}

After the successful piloting of advanced practice credentialing, the program now operates under the formalized banner of "Advancing Practice", and the first round of credentialing opened in March 2018. ${ }^{23}$ Using the NCSFP, this credentialing program recognizes pharmacists at all stages of advancement (Table 1). ${ }^{16}$ All pharmacists can undertake career mapping to identify areas of strength and improvement, which encourages professional development and progression for the purposes of delivering better health care to Australians. Since March 2018, more than 60 pharmacy practitioners have been recognized according to the 3 stages of advancement. ${ }^{24}$

\section{Portfolio Submission}

A portfolio is a "formal documentation of training, achievements and experience". ${ }^{25}$ It is an accepted evaluation method used to provide evidence of competencies, including professional behaviour, practice-based improvements, research activities, and professional experience. ${ }^{25}$

As part of the Advancing Practice application, the submission of a portfolio is required. The portfolio addresses the 5 competency domains, which are representative of key elements of pharmacy practice and are skills that are also seen in Canadian pharmacists. Furthermore, the portfolio is made up of written 
statements, with supporting evidence, that demonstrate the applicant's stage of performance and impact of their work for each competency. The portfolio is reviewed by 2 experienced and trained pharmacists for independent evaluation and feedback. A portfolio-building guide is available to support applicants and to describe the criteria for portfolio evaluation and credentialing. ${ }^{26}$

The practice of self-reflection and evaluation that occurs during portfolio building further serves to identify areas for career advancement and professional development. Notably, reflective practice portfolios are required for documenting continuing professional development for ongoing registration as a pharmacist in both Canada and Australia. ${ }^{27-30}$

\section{Advancing Practice in Education}

The advancing practice agenda in Australia remains relatively new, so it has been imperative to raise the profile of the benefits of the credentialing pathway and of working toward more advanced practice. Educators have an important role in helping move the profession away from focusing on a record of professional education, to a more reflective approach of life-long learning, including maintenance of a portfolio. Universities are incorporating portfolio-based assessments that include elements of continuing professional development into their undergraduate and postgraduate studies. ${ }^{31}$ For example, Monash University in Melbourne, Australia, has incorporated a capstone unit (Professional Practice Portfolio) in the Master of Clinical Pharmacy degree. Students develop a portfolio consistent with the Advancing Practice portfolio-building guide, collating evidence from their educational units and workplace experience and mapping it against the NCSFP. They obtain experience writing context and impact statements, and their portfolios are independently evaluated, often by Advanced Practice Pharmacists. In the undergraduate (entry-to-practice) program at Monash University, reflective practice is incorporated into the curriculum. Students write regular skills-based reflections and develop personalized learning plans, then receive individualized feedback. This activity prepares graduates for the need to maintain a portfolio from day 1 of practice.

\section{Current Challenges with Definitions of Advanced Practice and Specialization}

A key means of developing an advanced practice framework, as noted by the Australian experience, is having clear definitions of advanced practice and specialization. A 2015 report describing advanced practice and specialization in pharmacy noted that the definitions and understanding of these 2 terms varied greatly throughout the world. ${ }^{8}$ This variation was echoed by the Needs Assessment of Specialization in Pharmacy in Canada, which noted that the definitions of advanced practice and specialization are critical to establishing formal recognition of pharmacists. ${ }^{32}$ Without clear definitions, there may be confusion among the profession, the public, and other health practitioners. Furthermore, the variation in definitions has created challenges in obtaining international harmony across the profession for the purposes of implementing frameworks for advanced practice recognition. In response to this problem, Australia's NCSFP uses scope of practice and performance level to describe the differences between specialty and advanced practice, respectively (Figure 1). ${ }^{16,33}$ Advanced practice generally refers to a higher level of performance, whereas specialty practice refers to a narrower, focused scope of practice.

In defining advanced pharmacist practice, the Needs Assessment of Specialization in Pharmacy in Canada adopted the APPF's definition of advanced practice., ${ }^{9}, 32$ Although the Needs Assessment recognized the importance of distinguishing between advanced pharmacist practice and specialty practice, it did include components of advanced practice within its definition of pharmacist specialists. It defined pharmacist specialists as pharmacists who "maintain an active clinical practice that is limited to a particular type of patients ..., part of the body ..., or location of practice. ... Pharmacy specialization requires an advanced body of knowledge distinct of the general practitioner and a specialized or enhanced depth of competency including knowledge, skills, attitudes and accountabilities based on the physical, social, and health sciences, sufficient to manage the most complex of cases and provide clinical leadership in the field." 32 Despite the lengthy definition of pharmacist specialists used in the Needs Assessment, there are clearly elements of the Australian definition of advanced practice embedded within it. Both definitions highlight that advanced competencies are required, extending beyond just knowledge. Limitations of the definitions of advanced pharmacy practice and pharmacist specialists in the Needs Assessment include the potential confusion created by overlapping definitions, as well as the fact that pharmacist specialists appear to include clinical practitioners only.

Of note, some jurisdictions in Canada have job roles titled "Clinical Pharmacy Specialist", which generally relate to pharmacists with higher qualification, working in particular areas of focus. Likewise, some Australian settings have job roles that include the word "advanced". In both cases these terms are related to job titles rather than specific credentials for nominated pharmacists, further adding to the confusion of how a pharmacist specialist or advanced practice pharmacist would be identified. Credentialing of advanced practice is recognition of an individual pharmacist's performance, rather than the job in which they are employed.

\section{EVIDENCE}

\section{Impact on Clinical Outcomes}

The clinical skills of advanced pharmacy practitioners are acknowledged to be at higher levels than those of entry-level pharmacists. ${ }^{8}$ Unfortunately, because of the varying definitions of 


\begin{tabular}{|c|c|c|}
\hline \multicolumn{2}{|c|}{ Scope of Practice } & \multirow{3}{*}{ 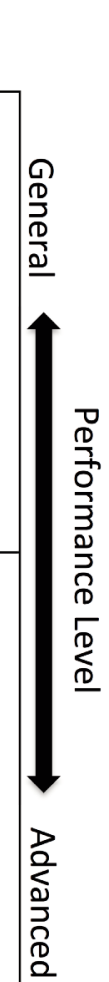 } \\
\hline $\begin{array}{l}\text { Generalist Pharmacist } \\
\text { Professional practice covers a } \\
\text { wide variety of consumers and a } \\
\text { broad range of medical conditions }\end{array}$ & $\begin{array}{c}\text { Focused Pharmacist } \\
\text { Professional practice covers a } \\
\text { broad rage of medical conditions } \\
\text { in a specific consumer group or is } \\
\text { directed to a limited range of } \\
\text { medical conditions across a wide } \\
\text { variety of consumers }\end{array}$ & \\
\hline $\begin{array}{l}\text { Advanced Generalist Pharmacist } \\
\text { Professional practice covers a } \\
\text { wide variety of consumers with } \\
\text { complex health care issues arising } \\
\text { from a broad range of medical } \\
\text { conditions }\end{array}$ & $\begin{array}{l}\text { Advanced Focused Pharmacist } \\
\text { Professional practice covers } \\
\text { complex health care issues arising } \\
\text { from a broad range of medical } \\
\text { conditions in a specific consumer } \\
\text { group or a limited range of } \\
\text { medical conditions across a wide } \\
\text { variety of consumers }\end{array}$ & \\
\hline $\begin{array}{l}\text { Figure 1. Using scope of practice } \\
\text { type. }{ }^{16} \text { Adapted, with permission, } \\
\text { Framework for Pharmacists in Aus } \\
\text { Australia. }\end{array}$ & $\begin{array}{l}\text { nd performance level to define pra } \\
\text { rom the National Competency Star } \\
\text { ralia. @ } 2016 \text { Pharmaceutical Socie }\end{array}$ & $\begin{array}{l}\text { ctice } \\
\text { dards } \\
\text { ty of }\end{array}$ \\
\hline
\end{tabular}

advanced and specialty practice used internationally, there are challenges in demonstrating the clinical impact of advanced practice pharmacists. Several studies of pharmacists working in specialized, focused roles have reported associated positive patient outcomes and cost savings. ${ }^{34-37}$ Unfortunately, these studies have not elaborated on the depth and breadth of the pharmacists' experience. To achieve recognition as an Advanced Practice Pharmacist in Australia, candidates must demonstrate their impact. In many cases, this impact includes changing practice, contributing to knowledge gaps via publication, and other activities known to have an impact on clinical outcomes. How we can more formally evaluate the impact of advanced practice on patient outcomes, beyond an individual or a small group basis, will be a challenge for the profession to address.

\section{Australian and Canadian Perspectives on Advanced Practice}

A survey of Australian pharmacists conducted by Jackson and others $^{38}$ in 2013, showed that 66\% (114 respondents) selfidentified as working at an advanced level of practice and a further $20 \%$ (34 respondents) identified as working toward advanced practice. However, it appeared that respondents did not understand that the advancing practice competencies extend beyond knowledge and also encompass communication, teamwork, professional leadership, education, and research. This result suggested a need to build awareness and understanding within the profession of the scope of advanced practice within the framework. This conclusion was reinforced by the finding that, of those pharmacists who considered they had been formally assessed as being advanced practitioners, many cited agencies that grant recognition on the basis of an assessment of knowledge or process, which would be insufficient for demonstrating advanced practice under the APPF.

A survey of Canadian pharmacists found that $48 \%$ of the 2084 respondents self-identified as a pharmacist specialist, as defined by the Needs Assessment of Specialization in Pharmacy in Canada. ${ }^{32}$ Furthermore, a survey conducted by the Canadian Society of Hospital Pharmacists (CSHP) in 2017 showed that $57 \%(114 / 199)$ of respondents reported working in an advanced practice role. ${ }^{39}$ It should be noted that the definition of an advanced practice role in the CSHP survey differed from the definitions used by the APPF and the Needs Assessment of Specialization in Pharmacy in Canada. 
Consistent with findings from the United Kingdom, the survey by Jackson and others ${ }^{38}$ also revealed that Australian pharmacists preferred the submission of a professional portfolio for assessment of advanced practice. Interestingly, these respondents were not in favour of evaluation by a written examination, aligned with other international viewpoints. ${ }^{38}$ Although at the time the second-highest preference for assessment method was "recognition of a prior qualification", it was decided that this would not be accepted as the sole piece of evidence required for credentialing as an advanced practitioner. ${ }^{38}$ Many applicants with a postgraduate qualification feature aspects of their degree as evidence in their portfolio, mapped against relevant competencies.

In the Canadian survey, the preferred method of certification was not explored; however, respondents were directly asked about their preferences for recertification via written examination, of which the majority were in favour. ${ }^{32}$ It is unclear how the skills that extend beyond knowledge could be evaluated in this format.

\section{International Perspectives on Advanced Practice}

The International Pharmaceutical Federation's (FIP's) Advanced Practice and Specialisation in Pharmacy Global Report 2015 collated information provided by participant countries regarding advanced and specialty practice around the world. ${ }^{8}$ The lack of a standard definition for advanced or specialty practice affected the information provided by the respondents. Eleven of the 17 countries that responded reported the availability of professional recognition of advanced practice and/or specialization. Professional recognition was offered in a number of forms, including formal credentials, protected titles and postnominal titles, a separate register, career progression tracks, and financial incentives. Formal credentialing was the standard professional recognition mechanism shared across the countries. Certification requirements were different in every case study and were typically a combination of examinations; peer reviews; postgraduate qualifications, certificates, or training courses; portfolio assessments; work experience; specialty residency programs; internships; workrelated theses; and scope of practice evidence.

\section{Applicability of Frameworks Globally}

The FIP report also demonstrated that despite some differences in pharmacy practice, there are several practice-related competencies with global applicability. ${ }^{8}$ The practice similarities between Canada and Australia are suggestive of this broad applicability. Work conducted by Udoh and others ${ }^{40,41}$ has shown that both content experts and practitioners across the globe found the advanced practice competencies of the UK's Royal Pharmaceutical Society Advanced Pharmacy Framework ${ }^{42}$ and the Australian APPF to be similar. These results support the notion of practice-related competencies with global relevance.
Published case studies indicate that the advanced and specialty frameworks of some countries are adopted and adapted from another country or profession. ${ }^{43,44}$ In addition to Australia's adaptation of the Competency Development and Evaluation Group's Advanced and Consultant Level Competency Framework, Singapore's specialist accreditation framework for pharmacists was developed in line with that country's medical and dental specialization frameworks. ${ }^{8}$

Building on the concept of global similarities in pharmacy practice, the FIP Global Advanced Development Framework was launched in September 2019. ${ }^{45}$ This framework is a validated tool to support professional development and recognition of the pharmacy workforce internationally. It maps 3 advanced practice stages across the following developmental competencies: "medicines expertise, leadership capabilities ..., managing health and professional delivery services and people, training and mentoring, and developing evaluation skills and innovation in health and professional service provision" ${ }^{45}$

\section{FUTURE DIRECTIONS}

\section{Learnings from Australia}

Engaging all pharmacy-related member organizations has been imperative to the successful implementation of a framework for advanced practice in Australia. Embedding the framework in the NCSFP and embedding reflective learning into education have also been instrumental in engaging the profession. ${ }^{16}$ At the same time, there have been numerous challenges in the credentialing system, largely relating to sustainability. Despite the survey results of Jackson and others, ${ }^{38}$ the perception among some pharmacists is that Advancing Practice is relevant to only a very small number within the profession, so many have not yet engaged in the process. Some sectors lack obvious drivers for pharmacists to pursue formal recognition of more advanced practice, such as links to career progression, remuneration, and employer expectations; however, this situation may be changing. Recently the Pharmaceutical Society of Australia released its Pharmacists in 2023 report, describing the changes needed to deliver safety and quality in the use of medicines. ${ }^{46}$ An accompanying report describes roles and remuneration and clearly links new roles for pharmacists exhibiting more advanced practice. ${ }^{47}$ It is expected this initiative will further acknowledge the importance of pharmacists demonstrating their level of performance. In addition, some hospitals now have well-described career progression pathways mirroring the advancement initially recognized by the APPF. ${ }^{48}$

\section{Advanced Practice in Canada}

In the previously described Advanced Practice and Specialisation in Pharmacy Global Report $2015,{ }^{8}$ the Canadian respondents made it clear that agreed definitions of advanced and specialty practice addressing practice scope, competencies, and 
responsibilities are important for pharmacists and other health care professionals. They reported that developing a "funding model" is important for planning a sustainable credentialing system in Canada. These respondents also recognized that the push for pharmacists' specialization must be based on improvements to patient care and within health systems. They also reported that pharmacists endorse the development of Canadian-specific accreditation programs for specialization but recognize that using international certification bodies might be a viable and sustainable option, considering the size of Canada's pharmaceutical workforce. ${ }^{8}$ Given the limitations associated with relying solely on exam-based credentialing, which has a strong focus on demonstrating knowledge rather than impact, it may be worth the profession in Canada reconsidering this option.

The system and processes in place in Australia and the United Kingdom are similar and reproducible and have been demonstrated to be comparable. Given the similarities in health care systems, workforce size, and practice scope, adaptation of an international credentialing system, as demonstrated in Australia and elsewhere, may be feasible in Canada.

\section{CONCLUSION}

To further optimize patient care within the Canadian health system, we require pharmacists to be working at a more advanced level. Formal recognition of advanced practice and support for progression of pharmacists through the use of a competency framework in Canada could assist in this endeavour. Australia has established a comprehensive framework and credentialing system that, given the similarities between the Canadian and Australian workforces and health care systems, could be adapted to the Canadian setting.

Many Canadian pharmacists perceive themselves as practising at a level that is beyond entry-to-practice. Building on the work that has already commenced in Canada, Australia, and beyond, an opportunity exists now to unite the profession and more formally recognize the contribution of the Canadian workforce. Furthermore, as advanced practice progresses across the globe, it is imperative that the profession begin to measure the clinical and economic impact of advanced practitioners. The profession must also consider how global harmonization of the definitions of advanced and specialty practice and of credentialing processes could unite and strengthen the international impact of the workforce.

\section{References}

1. Koné Pefoyo AJ, Bronskill SE, Gruneir A, Calzavara A, Thavorn K, Petrosyan $\mathrm{Y}$, et al. The increasing burden and complexity of multimorbidity. BMC Public Health. 2015;15:Article 415.

2. 1 in 5 Australians affected by multiple chronic diseases [media release]. Australian Institute of Health and Welfare; 2015 [cited 2020 Mar 15]. Available from: www.aihw.gov.au/news-media/media-releases/2015/august/ 1-in-5-australians-affected-by-multiple-chronic-di

3. Chronic disease and comorbidities. In: Australia's health 2016. Cat. no. AUS 199. Australian Institute of Health and Welfare; 2016 [cited 2020 Mar 15].
Available from: www.aihw.gov.au/getmedia/666de2ad-1c92-4db3-9c011368ba3c8c98/ah16-3-3-chronic-disease-comorbidities.pdf.aspx

4. Drug use among seniors in Canada, 2016. Canadian Institute for Health Information; 2018 [cited 2020 Mar 15]. Available from: www.cihi.ca/sites/ default/files/document/drug-use-among-seniors-2016-en-web.pdf

5. Page AT, Falster MO, Litchfield M. Pearson S, Etherton-Beer C. Polypharmacy among older Australians, 2006-2017: a population-based study. Med J Aust. 2019;211(2):71-5.

6. National health expenditure trends: 1975 to 2019. Canadian Institute for Health Information; 2019 [cited 2020 Mar 15]. Available from: www. cihi.ca/en/national-health-expenditure-trends-1975-to-2019

7. Health expenditure Australia 2017-18. Australian Institute of Health and Welfare; 2019 [cited 2020 Mar 15]. Available from: www.aihw.gov.au/ reports/health-welfare-expenditure/health-expenditure-australia-2017$18 /$ contents/data-visualisation

8. Advanced practice and specialisation in pharmacy: global report 2015. International Pharmaceutical Federation; 2015 [cited 2020 Mar 15]. Available from: www.fip.org/file/1397

9. An advanced pharmacy practice framework for Australia. Advanced Pharmacy Practice Framework Steering Committee; 2012 [cited 2020 Mar 15]. Available from: http://advancedpharmacypractice.com.au/download/ framework/advanced-pharmacy-practice-framework.pdf

10. Jorgenson D, Penm J, MacKinnon NJ, Smith J. Part 5: Future vision for the pharmacy profession. Can Pharm J. 2017;150(6):355-8.

11. What are the stages of advancing practice? Pharmacy Development Australia; 2018 [cited 2020 Mar 15]. Available from: https://advancingpractice.com.au/ \#1536825251509-2a93cbc3-c4f0

12. Jackson S, Martin G, Bergin J, Clark B, Stupans I, Yeates G, et al. An Advanced Pharmacy Practice Framework for Australia. Pharmacy (Basel). 2015;3(2):13-26.

13. Advancing practice: background and guiding principles. Pharmacy Development Australia; 2018 [cited 2020 Mar 15]. Available from: https://advancingpractice.com.au/wp-content/uploads/2018/11/advancingpractice-background-and-guiding-principles.pdf

14. Australian credentialed Advanced Practice Pharmacists (Adv. Prac. Pharm.) in the pilot program. Pharmacy Development Australia; 2019 [cited 2020 Mar 15]. Available from: https://advancingpractice.com.au/\#background

15. Matthews A, Adkins R, Clark B, Coombes I, Duggan C, Galbraith K, et al. Evaluation of practice portfolios for the credential of 'Advanced Practice Pharmacist' in Australia- pilot program [abstract]. Pharm Educ. 2015; 15(1):213.

16. National competency standards framework for pharmacists in Australia. Pharmaceutical Society of Australia; 2016 [cited 2020 Mar 15]. Available from: www.psa.org.au/practice-support-industry/national-competencystandards/

17. Moles R, Stehlik P. Pharmacy practice in Australia. Can J Hosp Pharm. 2015;68(5):418-26.

18. Canada's health care system. Government of Canada; 2016 [cited $2020 \mathrm{Mar}$ 15]. Available from: www.canada.ca/en/health-canada/services/canadahealth-care-system.html

19. Pharmacy workforce intelligence: global trends report. International Pharmaceutical Federation; 2018 [cited 2020 Mar 15]. Available from: www.fip.org/www/streamfile.php?filename=fip/PharmacyEducation/ Workforce_Report_2018.pdf

20. Australia's health workforce series: pharmacists in focus. Health Workforce Australia; 2014 [cited 2020 Mar 15]. Available from: http://iaha.com.au/ wp-content/uploads/2014/03/HWA_Australia-Health-WorkforceSeries_Pharmacists-in-focus_vF_LR.pdf

21. Pharmacists in Canada. Canadian Pharmacists Association; 2019 [cited 2020 Mar 15]. Available from: www.pharmacists.ca/pharmacy-in-canada/ pharmacists-in-canada/

22. Foundation residency. Society of Hospital Pharmacists of Australia; 2019 [cited 2020 Mar 15]. Available from: www.shpa.org.au/residency/foundation

23. New era for Australian pharmacy as Advancing Practice credentialing opens [news release]. Pharmacy Development Australia; 2018 [cited 2020 Mar 15]. Available from: https://advancingpractice.com.au/news-posts/new-era-foraustralian-pharmacy-as-advancing-practice-credentialing-opens/ 
24. Pharmacists credentialed by Advancing Practice since 2018. Pharmacy Development Australia; 2019 [cited 2020 Mar 15]. Available from: https://advancingpractice.com.au/\#background

25. Advanced and extended pharmacy practice: an environmental snapshot. Australian Pharmacy Council; 2013 [cited 2020 Mar 15]. Available from: https://www.pharmacycouncil.org.au/news-publications/apcpublications/advanced-and-extended-pharmacy-practice-publication

26. Advancing practice: portfolio building guide. Pharmacy Development Australia; 2018 [cited 2020 Mar 15]. Available from: https:// advancingpractice.com.au/wp-content/uploads/2019/03/advancing-practiceportfolio-building-guide.pdf

27. Registration standard: continuing professional development. Pharmacy Board of Australia; 2015 [cited 2020 Mar 15]. Available from: www.pharmacyboard. gov.au/Registration-Standards.aspx

28. CCP requirements. Alberta College of Pharmacy; 2019 [cited 2020 Mar 15]. Available from: https://abpharmacy.ca/ccp-requirements

29. Learning portfolio. Ontario College of Pharmacists; 2019 [cited 2020 Mar 15]. Available from: www.ocpinfo.com/practice-education/qa-program/ learning-portfolio/

30. Professional development and assessment program (PDAP). College of Pharmacists of British Columbia; 2019 [cited 2020 Mar 15]. Available from: www.bcpharmacists.org/professional-development-and-assessment-programpdap

31. Lucas C, Woulfe J, Lonie JM, Williams KA, Smith L. Pharmacy students' perceptions of ePortfolios in pharmacy education. Pharm Educ. 2019; 19(1):162-70.

32. Intergage Consulting Group/Blueprint for Pharmacy. Needs assessment of specialization in pharmacy in Canada. Canadian Pharmacists Association; 2015 [cited 2020 Mar 15]. Available from: www.pharmacists.ca/cpha-ca/ assets/File/pharmacy-in-canada/blueprint/Needs\%20Assessment $\% 20$ of $\% 20$ Specialization $\% 20$ in $\% 20$ Pharmacy $\% 20$ in $\% 20$ Canada $\%$ 20-\%20Final\%20Report.pdf

33. Council on Credentialing in Pharmacy. Scope of contemporary pharmacy practice roles, responsibilities, and functions of pharmacists and pharmacy technicians. J Am Pharm Assoc. 2010;50(2):e35-e69.

34. Lee H, Ryu K, Sohn Y, Kim J, Suh GY, Kim E. Impact on patient outcomes of pharmacist participation in multidisciplinary critical care teams: a systematic review and meta-analysis. Crit Care Med. 2019;47(9):1243-50.

35. Kaboli PJ, Hoth AB, McClimon BJ, Schnipper JL. Clinical pharmacists and inpatient medical care: a systematic review. Arch Intern Med. 2006; 166(9):955-64

36. Koshman SL, Charrois TL, Simpson SH, McAlister FA, Tsuyuki RT. Pharmacist care of patients with heart failure: a systematic review of randomized trials. Arch Intern Med. 2008;168(7):687-94.

37. Dalton K, Byrne $S$. Role of the pharmacist in reducing healthcare costs: current insights. Integr Pharm Res Pract. 2017;6:37-46.

38. Jackson S, Martin G, Bergin J, Clark B, Halstead P, Rowett D, et al. Advanced practice: a survey of current perspectives of Australian pharmacists. J Pharm Prac Res. 2015;45(2):186-92.

39. What patients and members told us about patient care: a report of surveys conducted in the fall of 2017. Canadian Society of Hospital Pharmacists; 2018 [cited 2020 May 19]. Available from: https://www.cshp.ca/sites/default/files/ Excellence/CSHP\%20Excellence_Member_Patient\%20Survey\%20Full_ Report_Final_August\%202018.pdf
40. Udoh AE. Identifying and evaluating foundation and advanced pharmacy practice competencies in a global context $[\mathrm{PhD}$ thesis]. University College London School of Pharmacy; 2016 [cited 2020 Mar 15]. Available from: https://discovery.ucl.ac.uk/id/eprint/1505718/1/Udoh_Arit_Thesis_ Original.pdf

41. Udoh A, Bruno A, Bates I, Galbraith K. Transnational comparability of advanced pharmacy practice developmental frameworks: a country-level crossover mapping study. Int J Pharm Pract. 2018;26(6):550-9.

42. The RPS advanced pharmacy framework. Royal Pharmaceutical Society; 2013 [cited 2020 Mar 15]. Available from: www.rpharms.com/Portals/0/RPS\% 20 document $\% 20$ library/Open\%20access/Frameworks/RPS\%20 Advanced\%20Pharmacy\%20Framework.pdf

43. Bates I, Bader LR, Galbraith K. A global survey on trends in advanced practice and specialisation in the pharmacy workforce. Int J Pharm Pract. 2020;28(2):173-81.

44. Bader LR, Bates I, Galbraith K. Trends in advanced practice and specialisation in the global pharmacy workforce: a synthesis of country case studies. Int J Pharm Pract. 2020;28:182-90.

45. FIP Global Advanced Development Framework: supporting the advancement of the profession [executive summary]. International Pharmaceutical Federation; 2019 [cited 2020 Mar 15]. Available from: www.fip.org/file/4331

46. Pharmacists in 2023: for patients, for our profession, for Australia's health system. Pharmaceutical Society of Australia; 2019 [cited 2020 Mar 15]. Available from: www.psa.org.au/advocacy/working-for-our-profession/pharmacistsin-2023/

47. Pharmacists in 2023: roles and remuneration. Pharmaceutical Society of Australia; 2019 [cited 2020 Mar 15]. Available from: www.psa.org.au/ advocacy/working-for-our-profession/pharmacists-in-2023-roles-andremuneration/

48. Medication services [Clinical Services Capability Framework service module; CSCF v3.2]. Queensland Health; 2016 [cited 2020 Mar 15]. Available from: www.health.qld.gov.au/_data/assets/pdf_file/0023/444326/cscfmedication.pdf

Rochelle M Gellatly, BSc(Pharm), PharmD, ACPR, BCPS, AdvPracPharm, is with the Pharmacy Department of Surrey Memorial Hospital, Surrey, British Columbia, and the Faculty of Pharmacy and Pharmaceutical Sciences, Monash University, Parkville, Victoria, Australia.

Kirsten Galbraith, BPharm, MClinPharm, AdvPracPharm, is with the Faculty of Pharmacy and Pharmaceutical Sciences, Monash University, Parkville, Victoria, Australia.

Competing interests: None declared.

Address correspondence to:

Dr Rochelle M Gellatly

Pharmacy Department

Surrey Memorial Hospital

1375096 Avenue

Surrey BC V3V 1 Z2

e-mail: rochelle.gellatly@fraserhealth.ca 